\title{
RBEP
}

\section{O ensino da Didática, das metodologias específicas e dos conteúdos específicos do ensino fundamental nos currículos dos cursos de Pedagogia}

José Carlos Libâneo

\section{Resumo}

Apresenta aspectos do ensino da Didática, das metodologias específicas e das disciplinas de conteúdos dos anos iniciais do ensino fundamental, visando analisar o lugar que elas ocupam em currículos do curso de Pedagogia e avaliar sua efetividade na formação profissional de professores. Em especial, avalia em que medida vem sendo valorizado, nesses cursos, o ensino de conteúdos das disciplinas do currículo do ensino fundamental (anos iniciais). A razão deste artigo se deve à constatação do quadro desolador da situação do ensino fundamental no País, o que remete à análise das condições de exercício profissional de professores, especialmente daqueles que atuam nas séries iniciais do ensino fundamental. Trata-se de pesquisa documental referente à estrutura curricular e às ementas de 25 instituições de ensino que mantêm curso de Pedagogia.

Palavras-chave: formação de professores; curso de Pedagogia; Didática; metodologias de ensino; relação conteúdo-método. 


\section{Abstract \\ The teaching of Didactics and of specific methodologies and contents of primary education in the curricula of Pedagogy}

This paper presents aspects of the teaching of didactics, specific methodologies and subjects of the early years of primary education, in order to analyze their place in the curricula of Pedagogy and to evaluate their effectiveness in teachers training. In particular, this article evaluates to what extent the teaching of subjects of the primary school curriculum is being emphasized in these faculties. This study is motivated by the recurrently depicted bleak picture of primary education in Brazil, which inevitably leads to the need to analyze teachers' practice conditions, especially of those who work in the early years of elementary school. The study is based on a documentary research on the curriculum structure and summaries of 25 educational institutions that offer a Pedagogy course.

Keywords: teachers training; Pedagogy; Didactics; teaching methodologies; content-method relationship.

O presente texto é um recorte de pesquisa mais ampla sobre a situação da Didática, das metodologias específicas e disciplinas conexas e sua relação com a qualidade da formação profissional de professores nos cursos de Pedagogia do Estado de Goiás (Libâneo, 2009b). Para a coleta de dados, foi realizada pesquisa documental sobre a estrutura curricular e as ementas das disciplinas de todas as 25 instituições de ensino que mantêm curso de Pedagogia, sendo duas públicas (Universidade Federal de Goiás e Universidade Estadual de Goiás), duas fundações e 21 privadas. Na apresentação das informações, as disciplinas do curso de Pedagogia foram distribuídas em quatro categorias: fundamentos teóricos da educação, conhecimentos referentes ao sistema educacional, conhecimentos referentes à formação profissional específica e conhecimentos referentes às modalidades e níveis de ensino, acrescentadas de outros conhecimentos, pesquisa e trabalho de conclusão de curso e estágio supervisionado e atividades complementares (Quadro 1). Para essa categorização, foi utilizado, com algumas adaptações, o quadro de categorias apresentado no trabalho de Gatti e Nunes (2009). Na categoria "conhecimentos referentes à formação profissional específica", foram incluídos Didática, fundamentos e metodologias específicas, conteúdos do currículo do ensino fundamental e tecnologias educativas. 


\section{Quadro 1 - Categorias utilizadas para análise das grades curriculares e} respectivas disciplinas

\begin{tabular}{|c|c|}
\hline Categorias & Disciplinas \\
\hline $\begin{array}{l}\text { Fundamentos teóricos da } \\
\text { educação }\end{array}$ & $\begin{array}{l}\text { Filosofia da Educação, Sociologia da Educação, } \\
\text { Psicologia da Educação, História da Educação e } \\
\text { correlatas. }\end{array}$ \\
\hline $\begin{array}{l}\text { Conhecimentos referentes } \\
\text { aos sistemas educacionais }\end{array}$ & $\begin{array}{l}\text { Políticas Públicas em Educação, Estrutura e } \\
\text { Funcionamento do Ensino, Organização do Trabalho } \\
\text { Pedagógico, Gestão Escolar, Legislação do Ensino, } \\
\text { Currículo, Avaliação Educacional e correlatas. }\end{array}$ \\
\hline $\begin{array}{l}\text { Conhecimentos referentes } \\
\text { à formação profissional } \\
\text { específica }\end{array}$ & $\begin{array}{l}\text { Didática, Metodologias Específicas e Práticas } \\
\text { de Ensino, Conteúdos do Currículo do Ensino } \\
\text { Fundamental, Tecnologias da Educação e correlatas. }\end{array}$ \\
\hline $\begin{array}{l}\text { Conhecimentos referentes } \\
\text { às modalidades e níveis } \\
\text { de ensino }\end{array}$ & $\begin{array}{l}\text { Educação Especial, Educação de Jovens e Adultos, } \\
\text { Educação Infantil, Contextos não-escolares e } \\
\text { correlatas. }\end{array}$ \\
\hline Outros conhecimentos & Diversidade Cultural, Libras, etc. \\
\hline $\begin{array}{l}\text { Pesquisa e Trabalho de } \\
\text { Conclusão de Curso }\end{array}$ & $\begin{array}{l}\text { Pesquisa em Educação, Prática como Componente } \\
\text { Curricular, TCC (cf. Parecer CNE/CP n 28/2001). }\end{array}$ \\
\hline $\begin{array}{l}\text { Atividades } \\
\text { complementares e Outras } \\
\text { atividades }\end{array}$ & Resolução CNE/CP nº 1/2006. \\
\hline
\end{tabular}

Fonte: Gatti e Nunes (2009), com algumas adaptações.

O que nos propomos aqui é aprofundar, por meio da análise das grades curriculares e das ementas, o lugar destinado à Didática, às metodologias específicas e, de modo especial, ao estudo dos conteúdos das disciplinas ensinadas nas séries iniciais do ensino fundamental. Os dados trazidos à consideração foram os obtidos na pesquisa mencionada (Libâneo, 2009b).

\section{Composição geral da grade curricular e o lugar ocupado pela Didática, pelas metodologias específicas e pelos conteúdos dos anos iniciais do ensino fundamental}

O levantamento da composição da estrutura curricular dos cursos das 25 instituições de ensino forneceu dados sobre o número de horas atribuído a cada bloco de categorias (em média) em relação ao total de cada curso, possibilitando um cotejamento entre as médias de cada bloco e, assim, a avaliação da proporção de horas atribuídas à Didática, às metodologias específicas e aos conteúdos específicos do ensino fundamental em relação às demais disciplinas (Tabela 1). 
Tabela 1 - Instituições de ensino superior do Estado de Goiás que mantêm curso de Pedagogia - composição da estrutura curricular (\%) - 2009
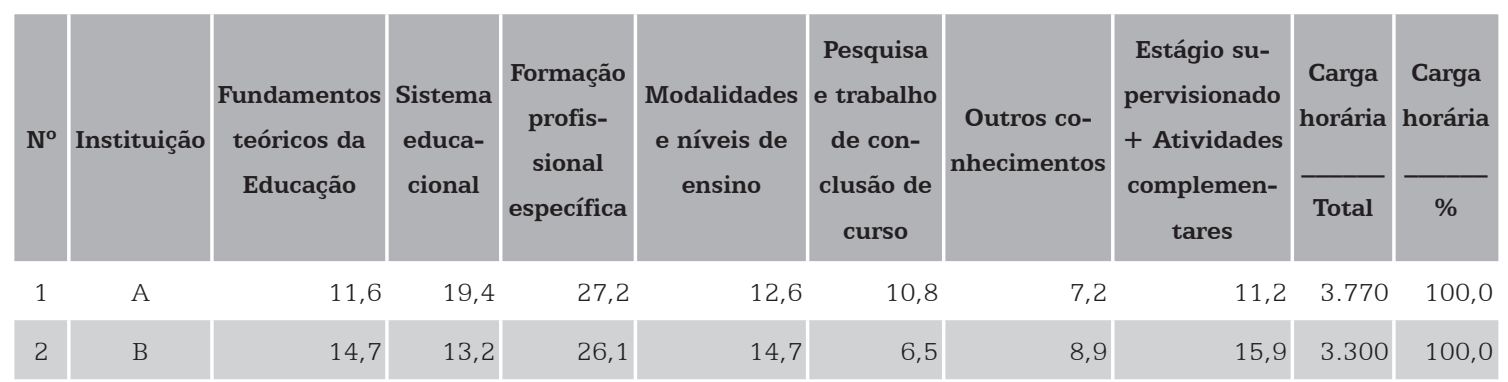

$11,6 \quad 19,4$

27,2

12,6

10,8

14,7

6,5

7,2

11,2

3.770

100,0

$3 \quad \mathrm{C}$

\begin{tabular}{l}
$14,7 \quad 13,2 \quad 26,1$ \\
\hline
\end{tabular}

4,4

8,9

15,9

$3.300 \quad 100,0$

$4 \quad$ D

\begin{tabular}{|l|l|}
\hline 22,8 & 17,8 \\
\hline 21,4 & 11,2 \\
\hline
\end{tabular}

23,9

$18,7 \quad 8,5$

25,8

9,5

6,8

6,7

$\begin{array}{lll}17,6 & 3.200 \quad 100,0\end{array}$

$5 \quad \mathrm{E}$

$6 \quad$ F

\begin{tabular}{|l|l|}
\hline 18,8 & 7,7 \\
\hline
\end{tabular}

23,4

$15,2 \quad 14,8 \quad 24,5$

23,7

9,8

4,4

7,4

\begin{tabular}{l|l|l}
20,3 & 3.200 & 100,0
\end{tabular}

$7 \quad$ G

12,9

15,2

9,9

\begin{tabular}{ll}
8 & $\mathrm{H}$ \\
\hline & $\mathrm{I}$
\end{tabular}

\begin{tabular}{|r|r|}
\hline 23,8 & 9,6 \\
\hline 17,4 & 10,7 \\
\hline
\end{tabular}

23,4

13,7

9,4

13

13,6

$14,5 \quad 3.205 \quad 100,0$

\begin{tabular}{|c|c|c|}
\hline \multicolumn{1}{|c|}{} & I \\
\hline 10 & J \\
\hline 11 & $\mathrm{~K}$ \\
\hline
\end{tabular}

$\begin{array}{ll}17,4 & 10,7\end{array}$

32,3

12,7
16,8

\begin{tabular}{rr}
24,3 & 12,6 \\
\hline 13,6 & 5,7
\end{tabular}

30,2
35,0

\begin{tabular}{rr}
8,3 & 3,8 \\
9,0 & 22, \\
\hline 10,3 & 5,1
\end{tabular}

\begin{tabular}{|c|c|c|c|c|c|c|c|c|c|c|}
\hline 12 & $\mathrm{~L}$ & 18,2 & 15,6 & 26,8 & 10,3 & 5,1 & 4,4 & 19,6 & 3.224 & 100,0 \\
\hline 13 & $\mathrm{M}$ & 15,5 & 13,6 & 32,9 & 9,3 & 2,1 & 7,8 & 18,8 & 3.200 & 100,0 \\
\hline 14 & $\mathrm{~N}$ & 18,2 & 17,7 & 28,8 & 4,6 & 11,3 & 5,4 & 14,0 & 3.360 & 100,0 \\
\hline 15 & $\mathrm{O}$ & 13,1 & 5,7 & 28,1 & 13,4 & 16,7 & 2,3 & 20,7 & 3.200 & 100,0 \\
\hline 16 & $\mathrm{P}$ & 21,7 & 12,7 & 31,4 & 8,7 & 7,5 & 5,5 & 12,5 & 3.200 & 100,0 \\
\hline 17 & Q & 14,7 & 17,5 & 31,5 & 10,0 & 7,5 & 6,3 & 12,5 & 3.200 & 100,0 \\
\hline 18 & $\mathrm{R}$ & 13,8 & 14,5 & 39,5 & 9,0 & 3,6 & 3,2 & 16,4 & 3.280 & 100,0 \\
\hline 19 & $\mathrm{~S}$ & 16,4 & 10,8 & 25,7 & 12,3 & 8,1 & 6,5 & 20,2 & 3.430 & 100,0 \\
\hline 20 & $\mathrm{~T}$ & 25,1 & 15,2 & 23,3 & 8,7 & 4,9 & 3,1 & 19,7 & 3.210 & 100,0 \\
\hline 21 & $\mathrm{U}$ & 23,7 & 13,1 & 28,6 & 5,3 & 9,6 & 3,7 & 16,0 & 3.200 & 100,0 \\
\hline 22 & V & 23,2 & 21,9 & 23,0 & 14,8 & 2,3 & 1,5 & 13,3 & 3.296 & 100,0 \\
\hline 23 & $\mathrm{X}$ & 22,2 & 8,6 & 27,4 & 9,4 & 8,6 & 5,1 & 18,7 & 3.110 & 100,0 \\
\hline 24 & $\mathrm{Y}$ & 12,9 & 7,2 & 34,0 & 4,5 & 12,0 & 14,4 & 15,0 & 3.340 & 100,0 \\
\hline 25 & Z & 18,6 & 6,9 & 29,9 & 4,6 & 4,6 & 16,2 & 19,2 & 3.120 & 100,0 \\
\hline \multicolumn{2}{|c|}{ Média } & 18,4 & 12,5 & 28,2 & 10,0 & 8,3 & 6,5 & 16,1 & 3.283 & 100,0 \\
\hline
\end{tabular}

\begin{tabular}{l|l|l|}
\hline 18,2 & 15,6 & 26,8 \\
\hline 15,5 & 13,6 & 32,9
\end{tabular}

26,8
32,9

10,9

\begin{tabular}{|c|c|c|c|}
\hline 7,3 & 15,1 & 3.200 & 100,0 \\
\hline
\end{tabular}


A porcentagem apurada por categoria corresponde ao número de horas (em média) por bloco de categorias, em relação à carga horária total de cada curso, que, conforme as Diretrizes Curriculares Nacionais para o Curso de Pedagogia, licenciatura (instituídas pela Resolução CNE/ CP n 1/2006), é, no mínimo, de 3.200 horas (sete cursos ultrapassam essa carga horária mínima, chegando a 3.400/3.700h). Verifica-se que as disciplinas correspondem a 83,9\% da carga horária, restando 16,1\% para as horas de estágio supervisionado (entre 300h e 450h) e de atividades teórico-práticas e/ou atividades complementares, conforme a legislação mencionada (com pequenas variações em cada instituição).

Embora em termos proporcionais o bloco "fundamentos teóricos da educação" tenha menos horas em média do que as disciplinas do bloco "formação profissional específica" (18,4\% e 28,2\%, respectivamente), uma observação mais atenta das grades curriculares referente ao número de horas das disciplinas de cada bloco mostra bastante variação entre as instituições em relação ao peso dado a esses dois conjuntos. Entre as 25 instituições de ensino, 5 têm porcentagem de carga horária em torno de 24\% para disciplinas "teóricas" e 34,7\% para disciplinas de conhecimentos específicos, ultrapassando em muito a média. Verifica-se também que, em cinco instituições, esses dois blocos somam, cada um, cerca de 23\% da carga horária total do curso, ou seja, as porcentagens entre as duas categorias são praticamente iguais. O que explica essas diferenças? Está claro que as instituições possuem diferentes visões dos objetivos de formação e diferentes ênfases no tocante aos conhecimentos necessários à formação profissional. Isso pode ser explicado pelo visível dissenso existente hoje entre pesquisadores, intelectuais, técnicos de órgãos públicos, militantes de associações e sindicatos do campo da educação acerca dos objetivos e funções da escola pública. Por outro lado, é sabido que a legislação educacional sobre o sistema de formação de professores é confusa, fragmentada, frequentemente com orientações legais superpostas, levando as instituições a fazerem seus próprios arranjos curriculares. Com isso, é razoável supor, também, que essas decisões curriculares nem sempre são "teóricas" e nem correspondem a uma proposta explicitada de escola ou de ensino, prevalecendo interesses locais, práticas corporativas, ou, simplesmente, decidindo por escolhas convencionais.

A presença nos currículos de disciplinas de "fundamentos" e disciplinas voltadas ao exercício profissional do professor leva a supor que as primeiras teriam a função de prover ao futuro professor os elementos teóricos da profissão, e as segundas, os de formação para as demandas da prática docente na escola e na sala de aula. No entanto, um ligeiro olhar sobre as ementas permite concluir que é muito tênue a relação das disciplinas de "fundamentos" com as práticas, enquanto as disciplinas referentes à formação profissional, em boa parte, não recorrem aos "fundamentos" e, frequentemente, elas próprias passam a impressão de que "ficam na teoria", desdenhando o "que" e o "como" ensinar. Ao se acreditar que um dos princípios propalados entre professores formadores e pesquisadores é a relação teoria-prática, seria desnecessário comparar as porcentagens entre 
disciplinas de "fundamentos" e disciplinas de "conhecimentos profissionais específicos"; umas e outras expressariam essa relação naturalmente. No entanto, como se constata a separação entre teoria e prática e considerandose que a função precípua do curso de Pedagogia, tal como estabelecido na legislação em vigor, é a formação de professores, pode-se afirmar que no conjunto dos cursos analisados a proporção de horas destinadas à "formação específica" em relação aos outros quatro blocos é pequena. Com efeito, enquanto os demais blocos somam 55,7\% (fora "estágio, atividades complementares"), a "formação específica" tem $28,2 \%$.

Considere-se também como questão problemática que o bloco "conhecimentos do sistema educacional" possui em média 12,5\% da carga total de horas dos cursos, mas há sete cursos com média em torno de 7\% e sete com média em torno de $21 \%$, ou seja, uns abaixo e outros acima da média das 25 instituições. Essa categoria corresponde aos conhecimentos que, segundo a legislação vigente, destinam-se a "aplicação de princípios da gestão democrática em espaços escolares e não-escolares" e "observação, análise, planejamento, implementação e avaliação de processos educativos e de experiências educacionais...". Na prática, as disciplinas arroladas nesta categoria, principalmente aquelas cuja porcentagem de horas está acima da média, contribuem para a fragmentação e a sobrecarga do currículo, além de manterem a controvertida ideia do "docente gestor" criada pela Associação Nacional pela Formação dos Profissionais da Educação (Anfope), como se o curso de Pedagogia conseguisse formar no mesmo currículo o professor, o gestor de sistemas educacionais ou de escolas e o pesquisador (cf. Libâneo, 2006).

Essas considerações sobre a composição da estrutura curricular e o lugar ocupado pelas disciplinas de formação específica coincidem com uma das conclusões do estudo de Gatti e Nunes (2009, p. 54): "o currículo proposto pelos cursos de formação de professores tem uma característica fragmentária, apresentando um conjunto disciplinar bastante disperso". A porcentagem de horas destinadas à Didática, às metodologias específicas e disciplinas conexas (28,2\% em média) indica que a formação profissional específica é, na maior parte das instituições, pouco valorizada no conjunto do curso, além de predominarem nas ementas conteúdos bastante genéricos, com pouca densidade teórica. Isso não quer dizer que se deveria dar mais peso a este conjunto de disciplinas e não, por exemplo, aos "fundamentos da educação", mas que a estrutura curricular falha ao dedicar à formação profissional específica menos de um terço do total da carga horária do curso e, ainda assim, as ementas não evidenciam articulação entre os "fundamentos", os conteúdos e as metodologias de ensino das disciplinas.

\section{Didática, metodologias específicas e conteúdos específicos do ensino fundamental: denominações e ementas}

Neste tópico, apresentaremos as denominações atribuídas nas grades curriculares das 25 instituições à Didática e às metodologias das 
disciplinas e suas respectivas ementas, verificando também a presença de disciplinas voltadas para os conteúdos específicos dos anos iniciais do ensino fundamental.

\section{A Didática}

A Didática está presente em todas as grades curriculares, embora com denominações diferentes: Didática (10); Didática e Formação de Professores (4); Didática Fundamental (3); Didática Geral (2); Didática e Prática Educativa nas Séries do Ensino Fundamental (1); Fundamentos de Didática (1); Pesquisa e Prática Pedagógica (1); Processos DidáticoPedagógicos (1); Pedagogia: Saber Docente e Rede de Saberes (1); Didática para o Ensino Fundamental e Didática para o Ensino Médio (1).

A existência de adjetivações, a mudança no título da disciplina, as alterações de conteúdo e a introdução de conteúdos não convencionais parecem indicar esforços de mudança ou inovação no conteúdo da Didática, mas, quando analisados os termos das ementas, pouco se alteram em relação aos conteúdos convencionais.

A análise dos tópicos incluídos nas ementas mostra que ao menos 70\% delas expressam uma didática instrumental, a despeito do notório desenvolvimento da pesquisa em Didática. No geral, elas descrevem conhecimentos técnicos, mormente modelos de planejamento e de técnicas, redigidas com pouca densidade teórica, de modo genérico e pouco aprofundado. Os temas mais constantes são planejamento de ensino, conteúdos e métodos, relação professor-aluno e avaliação, como se pode verificar nestes exemplos.

Conceito de Didática. Competências para ensinar. Estruturação do trabalho docente. Planejamento educacional: objetivos e conteúdos de ensino, métodos, estratégias e técnicas de ensino. Avaliação da aprendizagem.

Fundamentos (filosóficos, históricos, sociológicos, psicológicos da Didática, epistemológicos), a estruturação do trabalho docente, dinâmica da prática pedagógica. Planejamento e elementos constitutivos: objetivos, conteúdos, estratégias/procedimentos, técnicas, recursos. Avaliação. Relação professor-aluno.

As ementas que se diferenciam, não mais do que duas, são as que, além dos temas convencionais, indicam relações entre os vários elementos do ensino, por exemplo, "as relações dialéticas fundamentais do processo de trabalho docente: sujeito/objeto; teoria/prática; conteúdo/forma; ensino/aprendizagem; conhecimento/conhecer; sucesso/fracasso; professor/ aluno; aluno/aluno" ou "a contribuição das teorias do conhecimento, da cognição, e as metodologias específicas das ciências".

Além da persistência do caráter instrumental, as ementas mantêm uma concepção de Didática centrada na atuação do professor ou nos procedimentos, sem incorporarem, efetivamente, concepções que unem 
o ensino à aprendizagem e outros temas contemporâneos presentes na produção bibliográfica da área, como a importância dos contextos socioculturais, o papel dos meios de comunicação e informação, as características sociais e culturais dos alunos. Também é imperceptível nelas a presença dos conteúdos das disciplinas de "fundamentos" (sociologia, psicologia, etc.). Presume-se pouca preocupação dos docentes dessas disciplinas com o seu significado para o trabalho do professor em sala de aula e, da parte dos docentes de Didática, dificuldade de identificação ou pouco preparo teórico para identificar os elementos da sociologia e da psicologia para o ensino e a aprendizagem. Se os atuais professores de Didática dos cursos analisados são provenientes de cursos de Pedagogia, é possível que parte da prevalência de um modelo demasiado convencional de conteúdo de Didática se explique pela decadência na qualidade teórica desses cursos (cf. Libâneo, 2006).

\section{As disciplinas de metodologias específicas}

As metodologias específicas referem-se às disciplinas que suprem o futuro professor de bases metodológicas e procedimentais para ensinar os conteúdos do currículo dos anos iniciais do ensino fundamental, ou seja, Língua Portuguesa, Matemática, Ciências Naturais, História, Geografia, Arte, Educação Física. Tais disciplinas estão presentes em todos os cursos pesquisados, com uma grande variedade de denominações e número de horas. São as seguintes as denominações, conforme grade curricular de cada instituição: fundamentos e metodologia (ou métodos) de Língua Portuguesa, Ciências, Matemática, etc. (9); conteúdos e metodologia (ou métodos) do ensino de... (4); fundamentos teóricos e metodológicos de... (2); metodologia do ensino de... (3); metodologia e fundamentos de... (2); fundamentos (ou bases) epistemológicos(as) e metodológicos(as) de... (2); fundamentos metodológicos de... (2). Cinco instituições acrescentam fundamentos e metodologia de Educação Física e seis, de Arte.

Conforme se observa na descrição das ementas, as denominações acima se equivalem, isto é, prevalece nelas a ideia de que "fundamentos" referem-se a princípios básicos nos quais se deve apoiar o ensino das disciplinas, sem relacioná-los aos conteúdos específicos do ensino fundamental a serem ensinados nas escolas. Ressalve-se apenas que há, em poucas instituições, a disciplina "Oficina Multidisciplinar" para Ciências Naturais, Arte, História e Geografia, que expressa aproximações explícitas entre metodologia e conteúdos. Vejamos, a seguir, como aparecem as ementas das disciplinas de "fundamentos e metodologias".

\section{Fundamentos e metodologia da Língua Portuguesa}

As ementas desta disciplina mostram que é respeitada sua especificidade, mas a maioria delas identifica os "fundamentos" com princípios genéricos 
que estão por trás da constituição da matéria sem referência explícita aos conteúdos a serem ensinados aos alunos, como se pode notar nestas duas:

Fundamentos metodológicos do ensino de Português na $1^{\mathrm{a}}$ fase do ensino fundamental e educação infantil. Principais problemas de aprendizagem. Comunicação oral. Didática de conhecimento linguístico. Didática da comunicação e expressão em Língua Portuguesa. Leitura informativa e pesquisa bibliográfica.

Produção e reprodução evolutiva da Língua Portuguesa: aspectos fonéticos e fonológicos, morfológicos, sintáticos, lexicais, semânticos, pragmáticos e discursivos, na educação infantil e no ensino fundamental.

Em uma ou outra instituição, observa-se a tentativa de demarcar tópicos mais específicos, que, no entanto, não asseguram o ensino dos conteúdos a serem ministrados nas escolas. Por exemplo:

Conteúdos e metodologia. Aspectos gramaticais: acentuação, concordância nominal e verbal. Estudo funcional da ortografia, pontuação e gramática a partir do texto. Narração, dissertação. A produção textual literária e prática: narração, dissertação. Desenvolvimento da expressão oral e escrita. Recursos didáticos e instrumentos de avaliação da aprendizagem em Língua Portuguesa. Os Parâmetros Curriculares Nacionais para o ensino da Língua Portuguesa. Análise e seleção de livros didáticos.

Dezoito instituições incluem na grade curricular a disciplina Língua Portuguesa, outras introduzem denominações como alfabetização ou leitura e interpretação de textos, mas nenhuma delas contempla os conteúdos específicos a serem ensinados nas escolas.

\section{Fundamentos e metodologia de Matemática}

As ementas, em sua maioria, apresentam os elementos metodológicos da Matemática, às vezes com alguma menção à epistemologia da disciplina, mas raramente em articulação com o conteúdo específico.

Análise de procedimentos de ensino-aprendizagem de Matemática para as séries iniciais. O processo de ensino, avaliação e materiais didáticos, estudos dos conteúdos, métodos e materiais didáticos. Elaboração e discussão de propostas alternativas para o ensino da Matemática.

Fundamentos teóricos e metodológicos dos conteúdos (conceitos) matemáticos nos anos iniciais do ensino fundamental. Visão histórica e epistemológica do conhecimento matemático. A função social dos conteúdos matemáticos. A Matemática no currículo, na legislação e em diferentes enfoques teóricos metodológicos. Elaboração de propostas metodológicas para a Matemática nos anos iniciais do ensino fundamental. A avaliação da aprendizagem matemática.

Compreender os conceitos básicos da Matemática elementar, dando ênfase ao enfoque lógico das demonstrações e da solução de problemas, visando à construção do alicerce para a licenciatura no ensino fundamental. 


\title{
Fundamentos e metodologia de Geografia
}

Das 25 grades curriculares analisadas, 16 trazem fundamentos e metodologia de História e Geografia separadamente, enquanto nove as agrupam em uma só disciplina (duas com a denominação de ciências sociais e duas, de ciências humanas). A maioria das ementas segue o modelo descritivo e genérico, com raras menções aos temas e procedimentos investigativos próprios dessas disciplinas.

\begin{abstract}
Objetivos e função social do ensino de Geografia. Formação de conceitos. Estudo de conteúdos e processos de ensino e aprendizagem em Geografia nos anos iniciais do ensino fundamental. Elaboração de propostas pedagógicas e recursos didáticos para a Geografia. A avaliação da aprendizagem.
\end{abstract}

Pressupostos teóricos do ensino de Geografia. Análise dos conteúdos da proposta oficial para o ensino de Geografia nos anos iniciais do ensino fundamental. Conteúdos e metodologias específicas para aplicação em ambientes escolares e não escolares.

Sete ementas dão indicações, embora resumidas, de temas como "construção da noção de espaço e a relação entre Geografia e meio ambiente", "conceitos de paisagem e espaços geográficos", "formação do conceito de espaço pela criança e o estudo do meio". Quatro delas explicitam uma perspectiva metodológica associada à dimensão epistemológica quando indicam, uma, a apropriação dos conceitos de paisagem e espaços geográficos, outra, "princípios teórico-metodológicos dos conteúdos de Geografia e História: grupos sociais, espaço e suas relações sociais, tempo e suas relações sociais, cartografia, normas, socialização".

\section{Fundamentos e metodologia de História}

As observações feitas sobre as ementas de Geografia valem para as de História, quanto à descrição genérica. Algumas ementas fazem menção a conteúdos específicos, mas não os explicitam em termos de conceitos ou vínculos com a metodologia.

Análise de conteúdos e procedimentos de ensino e aprendizagem da História para os anos iniciais do ensino fundamental. O processo de ensino, seleção de conteúdos, métodos e materiais didáticos. Elaboração e discussão de propostas alternativas para o ensino dessa área de conhecimento.

Conhecimentos históricos: características e importância social. Fundamentos da historiografia: paradigmas atuais. Aprender e ensinar História nas séries iniciais do ensino fundamental. Os Parâmetros Curriculares Nacionais para o ensino de História. Objetivos e conteúdos específicos: organização e sequência. Aspectos didático-metodológicos. Análise da inter-relação entre conteúdo específico e demais áreas curriculares e os temas transversais. Critérios de avaliação. Livros didáticos.

Pressupostos teórico-metodológicos da História e o conhecimento histórico escolar. Pesquisa histórica e pesquisa no ensino de História. 
História do ensino de História. Procedimentos metodológicos no ensino de Historia. Novas linguagens no ensino de História. Construção de conceitos históricos e de noções de tempo. Uso de fontes históricas como recursos didáticos. Análise de material didático em História. Concepção e instrumentos de avaliação no ensino de História. Práticas interdisciplinares: produção de materiais didáticos em História.

\section{Fundamentos e metodologia de Ciências}

A pesquisa pedagógica no ensino de Ciências tem uma boa tradição em nosso País, e isso parece se refletir, ao menos, em dez das ementas analisadas, embora mantendo o caráter genérico, como a seguir.

Contextualização do ensino de Ciências Naturais nos anos iniciais do ensino fundamental. Objetivos e função social do ensino de Ciências. Concepção de ciência e ambiente. Estudo de conteúdos e procedimentos metodológicos. Elaboração de propostas metodológicas e recursos didáticos. A avaliação da aprendizagem em Ciências.

Foram encontradas ementas que acenam para uma perspectiva epistemológica e para a inclusão de conteúdos específicos, como esta:

Gênese da área de Ciências Naturais, conceitos e princípios básicos para a educação infantil e anos iniciais do ensino fundamental. Vinculação entre percepção espontânea infanto-juvenil e ciência formalizada; implicações para o trabalho pedagógico. Instrumentação do ensino de Ciências: planejamento, preparação e montagem de projetos para o ensino integrado de Ciências. Eixos temáticos, conforme os PCNs: terra, universo, vida e ambiente, ser humano e saúde, tecnologia e sociedade.

\section{As disciplinas de conteúdo específico para o ensino fundamental}

A questão aqui foi saber se nos currículos há disciplinas isoladas relacionadas com os conteúdos que serão ensinados às crianças (Alfabetização, Língua Portuguesa, Ciências, Matemática), já que constatamos que eles não são mencionados nas disciplinas de "fundamentos e metodologia". Em relação a Língua Portuguesa e Alfabetização, foram encontradas cinco denominações: Língua Portuguesa (18 instituições); leitura, interpretação e produção de textos (8); literatura infanto-juvenil (8); alfabetização e letramento (6); aquisição e desenvolvimento da linguagem (6); bases linguísticas da alfabetização (4); comunicação em Língua Portuguesa (2). Vejamos um exemplo da disciplina Língua Portuguesa:

Língua Portuguesa: Noções fundamentais acerca da relação entre linguística e ensino de gramática. A função da gramática normativa. Acentuação gráfica; crase; concordância nominal e verbal; colocação pronominal; ortografia; casos problemáticos de regência. Tipologia textual. Produção textual. Oficinas de texto: técnicas de leitura e produção de textos; uso de textos das disciplinas em curso, compreensão, aplicação e transposição de texto. Técnicas de resumo e resenha. 
É mais plausível supor que a intenção nessas disciplinas não seja contemplar os conteúdos específicos do ensino fundamental, mas melhorar o desempenho na língua do aluno do curso de Pedagogia como falante, não como futuro professor.

Em relação a Ciências, constam várias disciplinas isoladas com temas ligados a biologia e educação ambiental (5 instituições), biologia educacional e desenvolvimento humano, biologia educacional: saúde e nutrição, educação e ciências da natureza (uma instituição cada). Analisando as ementas, verifica-se que algumas trazem tópicos mais ligados a "fundamentos biológicos da educação", enquanto outras abordam temas específicos da Biologia, principalmente os relacionados com o meio ambiente. Não se trata, pois, de conteúdos específicos do ensino fundamental a serem ensinados às crianças.

Certas grades trazem conteúdos de Educação Física, algumas com intenções de prover aos professores o conhecimento de temas como corpo e movimento (5 instituições); corpo, cultura e expressividade (2); linguagem corporal na educação. Mas, também nessa área, trata-se mais de "fundamentos" do que de "conteúdos específicos".

Em relação à Arte no ensino fundamental, estão registradas disciplinas como arte e educação (8 instituições); artes, jogos e recreação, brinquedos e brincadeiras (5); educação lúdica, o lúdico e a educação (2); corpo, expressão e arte, jogos pedagógicos e ludicidade nos anos iniciais, em cujas ementas se manifestam as mesmas características já apontadas em outras disciplinas.

As tecnologias educativas constituem outro campo de estudos presente em 23 instituições. As denominações são variadas, porém o conteúdo gira em torno do tema "novas tecnologias da informação e comunicação" ou "tecnologias educativas". São disciplinas conectadas ao campo da Didática e, sem dúvida, incluem-se na categoria "conhecimentos profissionais dos professores", pois visam ao aprimoramento das práticas de ensino e aprendizagem.

Observa-se, pois, que, embora se registre o termo "fundamentos de..." ou "conteúdos de...", em que supostamente apareceriam os conteúdos específicos a serem ensinados nos anos iniciais, não é o que parece. Não há evidência em nenhuma ementa de que são contemplados, de forma sistemática, os conteúdos significativos de cada disciplina. Parece haver um entendimento entre os professores-formadores e entre os coordenadores de curso responsáveis pelo currículo de que os alunos já dominam esses conteúdos, trazidos do ensino médio, o que, como se sabe, não acontece.

Em síntese, a análise das grades curriculares e ementas referentes à Didática, às metodologias específicas e aos conteúdos dos anos iniciais do ensino fundamental traz constatações sumamente preocupantes para a formação profissional. Primeira: é visível a não articulação entre as metodologias e os conteúdos; as metodologias não apenas são tratadas independentemente do conteúdo que lhes dá origem, mas também em desconexão com os conteúdos, já que não são ensinados aos alunos 
"conteúdos" do ensino fundamental. ${ }^{1}$ Segunda: é possível supor que as metodologias são entendidas como algo que diz respeito à atuação do professor (centradas nele) sem destacar a interação aluno-objeto de conhecimento, isto é, sem ajudar os alunos a desenvolverem processos mentais (conceitos) que lhes permitam interagir com autonomia e criticidade com o mundo da natureza, da cultura e de si próprios. Numa visão mais severa, professores-formadores estariam valendo-se de uma concepção de metodologia de ensino como as formas de apresentar a versão simplificada dos conteúdos disciplinares para os alunos "absorverem" a matéria. Terceira: as disciplinas de "fundamentos da educação" aparecem muito tenuemente nas ementas de Didática e metodologias específicas, evidenciando mais uma vez a tão reiterada separação entre teoria e prática na formação. É razoável pensar que o problema real já não seria tanto o fato de um e outro conjunto de disciplinas não mostrarem vínculo teoria-prática, mas a prevalência de um modo de pensar cartesiano, que se reflete em aprendizagens parciais, fragmentadas, pouco imaginativas. Quarta: há a ausência, na maioria dos cursos analisados, de disciplinas de conteúdos específicos do ensino fundamental.

\section{Posições sobre saberes docentes, papel das escolas e Didática}

O tema deste texto diz respeito aos saberes docentes específicos ao exercício profissional de professores que atuarão nos anos iniciais do ensino fundamental. São conhecidos entre nós importantes estudos acerca desses saberes. Gauthier (1998, p. 29) e Tardif (2002, p. 36) escrevem que a prática dos docentes integra diferentes saberes com os quais mantêm diferentes relações: saberes disciplinares, saberes curriculares, saberes das ciências da educação, saberes da tradição pedagógica, saberes experienciais, saberes da ação pedagógica. Pimenta (1997, p. 42) sintetiza os saberes docentes em três tipos, articulados entre si: o saber da matéria, ou seja, o conhecimento que o professor possui sobre a disciplina que ensina; o saber pedagógico, que diz respeito ao conhecimento que resulta da reflexão confrontada entre o saber da matéria e os saberes da educação e da Didática; e o saber da experiência, construído a partir das experiências vivenciadas pelo professor. Também Shulman (2005, p. 11) aponta sete tipos de conhecimentos necessários aos professores: conhecimento do conteúdo; conhecimento didático geral; conhecimento do currículo; conhecimento didático do conteúdo; conhecimento dos alunos e de suas características; conhecimento dos contextos educativos; e conhecimento dos objetivos, das finalidades e dos valores educativos, e de seus fundamentos filosóficos e históricos.

Para Shulman, o conhecimento do conteúdo consiste não apenas nos estudos acumulados em cada uma das disciplinas, como também no saber acadêmico histórico e filosófico sobre a natureza do conhecimento implicado nessas disciplinas, na estrutura da matéria, nos princípios de sua organização conceitual, nos modos de problematizá-las. Ele escreve:

\footnotetext{
${ }^{1}$ Venho reiterando em recentes estudos a vinculação necessária entre Didática e epistemologia, mostrando que a Didática pensa a lógica das aprendizagens a partir da lógica do saber ensinado, ou seja, sua epistemologia. Sendo assim, o modo de se lidar didaticamente com algo depende do modo de se lidar epistemologicamente com algo. Nessa perspectiva, a Didática e as metodologias específicas deixam de ser apenas o ensino de melhores métodos ou técnicas de ensinar o conteúdo, como tem sido a idéia corrente (Libâneo, 2008, 2010a).
} 
Professores e professoras têm uma responsabilidade especial em relação ao conhecimento dos conteúdos da matéria que ensinam, por ser a principal fonte da compreensão da matéria para os alunos. A forma como é comunicada esta compreensão transmite aos estudantes o que é essencial e o que é periférico numa matéria. [...] Os professores também comunicam, conscientemente ou não, ideias acerca das formas de obter conhecimento em um campo, além de uma série de atitudes e valores que influem significativamente na compreensão de seus alunos. Esta responsabilidade põe, de modo especial, exigências tanto de uma profunda compreensão das estruturas da matéria por parte do professor quanto no que se refere às atitudes e ao entusiasmo do professor em relação ao que se está ensinando e aprendendo. Assim, estes diversos aspectos do conhecimento dos conteúdos tornam-se uma característica fundamental do conhecimento de base para o ensino (Shulman, 2005, p. 12).

Em estreita articulação com o conhecimento do conteúdo está o conhecimento didático do conteúdo, o qual "representa a ligação entre matéria e Didática, visando compreender como determinados temas e problemas podem ser organizados, representados e adaptados aos diversos interesses e capacidades dos alunos e expostos para seu ensino" (Shulman, 2005, p. 11).

Na tradição da teoria histórico-cultural, Davydov é explícito sobre a precedência dos conteúdos em relação a objetivos de ensino para o desenvolvimento mental dos alunos e, portanto, à escolha de metodologias de ensino. Esse autor sintetiza de forma precisa esse entendimento acerca dos conteúdos do conhecimento como base de referência para os métodos de ensino ao afirmar:

[...] A base do ensino desenvolvimental é seu conteúdo. Deste conteúdo são derivados os métodos (ou modos). Esta proposição exemplifica o ponto de vista de Vygotsky e Elkonin. "Para nós, escreveu Elkonin, tem importância fundamental sua idéia (i.e., de Vygotsky) de que o ensino realiza seu papel principal no desenvolvimento mental, antes de tudo, por meio do conteúdo do conhecimento a ser assimilado". Concretizando esta proposição, deve-se observar que a natureza desenvolvimental da atividade de aprendizagem no período escolar está vinculada ao fato de que o conteúdo da atividade acadêmica é o conhecimento teórico (Davydov, 1988a, p. 19). ${ }^{2}$

Em síntese, o domínio dos saberes disciplinares e o conhecimento pedagógico do conteúdo correspondem a duas das exigências fundamentais da formação profissional de professores, o que requer deles a compreensão da estrutura da matéria ensinada, dos princípios de sua organização conceitual, do caminho investigativo pelo qual vão se constituindo os objetos de conhecimento, e, ao mesmo tempo, o conhecimento pedagógico do conteúdo, ou seja, como temas e problemas podem ser organizados e trabalhados de modo a serem aprendidos pelos alunos.

Também conforme o referencial teórico da teoria histórico-cultural com base nas contribuições de Vygotsky e seguidores, o papel da escola é prover aos alunos a apropriação da cultura e da ciência acumuladas historicamente como condição para o seu desenvolvimento mental e torná-los 
aptos à reorganização crítica da cultura e da ciência. Para isso, ela deve estar comprometida, em primeiro lugar, com a atividade de aprendizagem dos alunos, visando a seu desenvolvimento cognitivo, afetivo e moral. Tal como expressa Vygotsky, trata-se de uma reconstrução individual da cultura num processo de interação com outros indivíduos: o que inicialmente são processos interpsíquicos se convertem em processos intrapsíquicos. Sendo assim, a intervenção pedagógica pelo ensino é imprescindível para o desenvolvimento cognitivo, afetivo e moral, por onde se opera a mediação das relações do aluno com os objetos de conhecimento. Mais especificamente, o professor possui papel ativo e intencional na promoção da aprendizagem dos alunos, atuando na formação de capacidades cognitivas por meio do processo mental do conhecimento presente nos conteúdos escolares, em associação com formas de interação social nos processos de aprendizagem lastreadas no contexto sociocultural das aprendizagens.

Dessa compreensão mais global sobre o papel das escolas decorrem traços distintivos da atividade de ensinar. Uma das características profissionais do professor consiste em atuar na zona de desenvolvimento proximal, isto é, ajudar os alunos na resolução de problemas que estão fora do seu alcance, desenvolvendo estratégias para que, pouco a pouco, possam resolvê-los de modo independente. Isso supõe uma boa capacidade de conversação do professor para fazer interagir na mente da criança aquilo que ela já sabe e aquilo que ele próprio vai introduzindo, de modo a criar formas de interação cognitiva que ampliem o desenvolvimento mental dos alunos. Os estudantes podem, então, chegar aos conceitos científicos ultrapassando os conceitos espontâneos, para o que é imprescindível o domínio dos conteúdos e do conhecimento didático dos conteúdos por parte do professor. Mas ele precisa conhecer, também, os processos lógicos e investigativos da disciplina, pois, nesta concepção de aprendizagem, aprender implica uma relação do aluno com os objetos do saber, de maneira que aprender é apropriar-se dos modos de compreender o objeto de estudo, ou seja, as ações mentais ligadas ao processo de constituição dos conteúdos. Para Davydov, a culminância esperada, do ponto de vista da aprendizagem, é que, ao aprender, o aluno se aproprie do processo histórico real de gênese e desenvolvimento do conteúdo e, assim, internalize métodos e estratégias cognitivas gerais da ciência ensinada, formando conceitos (procedimentos mentais operatórios), tendo em vista analisar e resolver problemas e situações concretas da vida prática (cf. Libâneo, 2004, 2009a). Isso significa, por exemplo, que, quando está ensinando "adição e subtração", o professor não vai repetir o caminho realizado pelo cientista (ou pesquisador) ao produzir o saber referente à Matemática, mas é preciso que capte, nesse saber, o movimento mental realizado para a sua produção. Esse é o caminho de ir além dos conceitos cotidianos, o senso comum, o que requer do professor saber articular conteúdos e metodologias investigativas da disciplina e, claro, dominar os conteúdos.

É nesse contexto teórico que se insere a Didática, as didáticas específicas e as metodologias de ensino enquanto disciplinas e 
instrumentos do trabalho docente. Elas sistematizam conhecimentos e práticas referentes a fundamentos, condições e modos e realização do ensino e da aprendizagem, visando ao desenvolvimento das capacidades mentais e à formação da personalidade dos estudantes. Por meio do ensino, o professor realiza plenamente seu trabalho quando ajuda o aluno a adquirir capacidades para novas operações mentais e a operar mudanças qualitativas em sua personalidade (Libâneo, 2009a).

Desse modo, o problema pedagógico-didático na educação escolar refere-se a, no mínimo, quatro aspectos: a) quais conteúdos contribuem para a formação das capacidades cognitivas dos alunos (conhecimento dos saberes disciplinares); b) como se organiza o conhecimento a ser trabalhado com os estudantes e como esse conhecimento pode ser melhor e mais eficazmente apropriado pelo aluno pela mediação (comunicação) do professor (conhecimento pedagógico do conteúdo); c) como o professor organiza e gere a sala de aula, especialmente as relações professoralunos e as formas como planeja e estrutura as situações pedagógicas e de aprendizagem; d) como a escola deve ser organizada enquanto espaço de práticas socioculturais, pedagógicas e institucionais.

\section{Considerações finais}

O artigo pretendeu traçar um quadro da Didática e das metodologias específicas e o lugar ocupado pelo conteúdo das disciplinas a ser ensinado nas séries iniciais do ensino fundamental em cursos de Pedagogia. Embora os dados coletados tenham se restringido a um dos Estados brasileiros - e, ainda assim, sem informações sobre o projeto pedagógico, os planos de ensino e o próprio funcionamento pedagógico cotidiano das instituições -, os achados permitem algumas conclusões sobre os formatos curriculares dos cursos e seu reflexo na formação profissional de professores.

Analisando os dados em relação à Didática, verificou-se que a proporção de horas/aula destinada ao bloco "formação profissional específica" corresponde a 28,2\% (em média), quase um terço da carga horária total dos cursos, informação que nos parece bastante expressiva para indicar a desvalorização da formação profissional específica do professor. Observa-se que o bloco "fundamentos teóricos" tem em média 18,4\% da carga horária total e o bloco "conhecimentos referentes ao sistema educacional" apresenta 12,5\% em média, somando 30,9\%. Poder-se-ia atribuir um crédito positivo aos currículos analisados por valorizarem as disciplinas de "fundamentos", visando prover ao futuro professor os elementos teóricos da profissão. No entanto, tal como mencionamos na pesquisa realizada,

[...] é muito tênue a relação das disciplinas de "fundamentos" com as práticas, enquanto que as disciplinas referentes à formação profissional, em boa parte, não recorrem aos "fundamentos" e, frequentemente, dão a impressão de que "ficam na teoria", desdenhando o "quê" e o "como" ensinar (Libâneo, 2009b). 
Sobre as ementas de Didática (ou denominação conexa), a análise do conteúdo mostra que ao menos 70\% delas expressam uma didática instrumental, no sentido de descrever conhecimentos técnicos, mormente modelos de planejamento e de procedimentos (regras de execução, técnicas). Os temas mais constantes são: planejamento de ensino, conteúdos e métodos, relação professor-aluno e avaliação. As ementas, com poucas exceções, apresentam características comuns, como frágil aporte teórico, caráter genérico e superficialidade, apenas variando a extensão do texto. Tal como registramos na pesquisa,

\begin{abstract}
[...] os limites da didática instrumental não estão na ênfase que põe nos modos de operar do professor, no "como fazer", nem mesmo no destaque ao planejamento de ensino e às técnicas. Isto tudo é necessário. O que falta são os aportes teóricos e epistemológicos para a compreensão da complexidade da mediação didática, que envolve a articulação entre saberes dos conteúdos específicos, saberes pedagógico-didáticos, saberes da experiência do aluno-futuro professor e, além disso, uma abordagem teoricamente fundamentada das metodologias e dos procedimentos de ensino em conexão com a cultura e o cotidiano escolar e o conhecimento local, tudo lastreado pela atitude investigativa (Libâneo, 2009b).
\end{abstract}

Quanto às disciplinas de "fundamentos e metodologias específicas", elas teriam por função, no currículo, suprir o futuro professor de bases metodológicas e procedimentais para ensinar os conteúdos das disciplinas dos anos iniciais do ensino fundamental, ou seja, Língua Portuguesa, Matemática, Ciências Naturais, História, Geografia, Arte, Educação Física. A pesquisa que vimos mencionando relata que,

[...] em relação aos tópicos das ementas, a análise mostra que prevalece nos projetos pedagógicos a concepção de 'fundamentos' como princípios básicos nos quais se apóiam as disciplinas, enfatizando apenas os aspectos metodológicos e procedimentais, quase sempre dissociados dos conteúdos. (Libâneo, 2009b).

Em relação aos conteúdos específicos do currículo do ensino fundamental, constatou-se que estão praticamente ausentes. Embora estejam registradas na grade curricular disciplinas que trazem os termos "fundamentos de..." ou "conteúdos de...", os conteúdos específicos a serem ensinados nos anos iniciais não aparecem, evidenciando uma grave lacuna na formação. A esse respeito, esta pesquisa confirma de modo ainda mais acentuado os resultados de Gatti e Nunes (2009, p. 54).

As grades curriculares e as ementas mostram indícios de que os currículos dos cursos de Pedagogia analisados apresentam sinais de uma estrutura fragmentária e dispersa. Há uma grande variação entre as instituições, no que se refere à denominação das disciplinas e à porcentagem de carga horária em cada uma das categorias das quais nos servimos para agrupar os dados. As ementas apresentam conteúdos demasiadamente simplificados e com pouca densidade teórica.

Ao mesmo tempo, é razoável levantar a suspeita de que a maioria dos cursos mantém a concepção curricular e a nomenclatura das 
disciplinas ainda baseadas na legislação do curso de Pedagogia em suas três regulamentações - 1939, 1962, 1969 - , reforçando as mesmas limitações sistematicamente diagnosticadas pela crítica ao longo das últimas décadas, e teimosamente inalteradas: dubiedade em relação à finalidade do curso (formação de professores? de gestores? de pesquisadores?), separação entre teoria e prática, entre conteúdo e método, etc. A Resolução CNE/CP n $n^{\circ} 1 / 2006$, que instituiu as Diretrizes para a Licenciatura em Pedagogia, trouxe mais confusão, pois, ao definir a docência como base da formação profissional, acabou por manter um currículo sobrecarregado de funções e de disciplinas dispersas, com objetivos ambíguos, em que as disciplinas e suas ementas se ressentem de referências mais explícitas à finalidade do curso, ou seja, a formação de professores (Libâneo, 2006). Está ausente a preocupação epistemológica, que se reflete na não articulação entre conteúdos e metodologias específicas das diferentes matérias, o que compromete, no trabalho do professor, o conhecimento didático do conteúdo.

Além disso, as disciplinas de "fundamentos" e as didáticas não conseguem sustentar no seu ensino a unidade entre teoria e prática, comprometendo a aplicação do que se ensina nos contextos reais da escola e da sala de aula. Não é nada casual a constatação de Gatti e Nunes (2009, p. 55) de que "a escola, enquanto instituição social e de ensino, é elemento quase ausente nas ementas, o que leva a pensar numa formação de caráter abstrato e pouco integrado ao contexto concreto onde o profissionalprofessor irá atuar".

De modo especial, a ausência de conteúdos específicos das matérias que irá ministrar às crianças torna o professor das séries iniciais despreparado para o ensino - o professor ensina o que sabe! Sem domínio do conteúdo que deveria ensinar, sem encantamento pelo conhecimento, sem uma cultura ampliada no campo da ciência e da arte, ele não poderá despertar nos alunos o gosto pelo saber, o entusiasmo pelo estudo. Do mesmo modo, será impossível atender à alínea VI inserida no art. $5^{\circ}$ da Resolução CNE/CP n ${ }^{\circ}$ 1/2006 sobre a abordagem interdisciplinar das disciplinas do ensino fundamental.

A ausência dos conteúdos do currículo do ensino fundamental reitera constatação já feita em 1976 por Valnir Chagas (1975, p. 66) sobre a "ausência de conteúdo na capacitação superior do professor primário", ou seja, há 35 anos se sabe que é precária a formação do professor para os anos iniciais quanto aos conteúdos que irá ensinar, e nada foi feito pelo sistema de ensino, pela legislação, pelos movimentos organizados da área da educação, pelos estudiosos da formação nesse nível em relação ao provimento de saberes disciplinares no currículo de formação.

Os problemas apurados na análise dos dados das pesquisas também apontam para o insucesso da adesão do governo brasileiro às políticas educacionais patrocinadas pelo Banco Mundial, desde a Conferência Mundial sobre Educação para Todos realizada em 1990 na Tailândia. Foi firmando-se nas sucessivas conferências mundiais o entendimento de que a escola para os pobres não precisa centrar-se na aprendizagem cognitiva 
dos alunos, mas na oferta de um pacote de competências mínimas como um "kit de sobrevivência". Por consequência, para uma escola destinada a atender necessidades de aprendizagem "mínimas" e a se organizar para fazer o acolhimento e a integração social das crianças, o professor não precisa de muito conteúdo: ele precisa desenvolver "habilidades" técnicas para "passar" o conteúdo pré-elaborado, sendo suficiente capacitá-lo com base num kit de habilidades docentes (cf. Torres, 2001; Libâneo, 2010b).

Os pesquisadores, legisladores e responsáveis pelo funcionamento do sistema de ensino precisam considerar os entraves que podem estar ocorrendo nos cursos de Pedagogia, comprometendo a formação de professores, entre eles: ementas genéricas, retóricas da Didática e das metodologias específicas, mantendo ainda forte apoio no caráter instrumental; desarticulação entre conteúdos e metodologias; falta do conteúdo das disciplinas específicas a serem ensinadas nas escolas; pouca contribuição das disciplinas de "fundamentos da educação" às metodologias de ensino; grades curriculares e ementas que não mostram, no geral, unidade e integridade do projeto pedagógico (embora este aspecto possa ser mais bem observado in loco). Enfim, é bastante plausível concluir que a Didática e as metodologias específicas, nessas condições apontadas, estejam sendo muito pouco relevantes para a atuação profissional dos professores.

Para educadores que apostam no papel imprescindível da educação escolar no desenvolvimento cognitivo, afetivo e moral dos alunos, faz diferença um ensino com conteúdos relevantes, especialmente para segmentos da população excluídos de bens materiais e culturais e das condições mínimas de cidadania. Pode-se discutir sobre critérios de relevância dos conteúdos, mas, de alguma forma, eles decorrem da experiência acumulada da humanidade em relação à ciência, à cultura, à arte. Segundo Gimeno Sacristán (2000, p. 100), "o cultivo da leitura e escrita, ou o provimento de uma visão científica do mundo, é papel das escolas, sendo pouco provável que outros agentes o façam nas condições e meios com os quais elas podem fazê-lo".

Uma escola desprovida de conteúdos culturais substanciosos e densos reduz as possibilidades de muitas crianças da oportunidade do desenvolvimento pleno de suas capacidades intelectuais e de sua personalidade. Se a educação escolar obrigatória é a base cultural de um povo, então são necessários professores que dominem os conteúdos da cultura e da ciência e os meios de ensiná-los, além de serem portadores de outros requisitos, como formação cultural, formação pedagógica e condições favoráveis de salário e de trabalho.

Esta pesquisa mostra a fragilidade do conjunto de saberes profissionais oferecidos aos futuros professores, a começar precisamente pela falta dos saberes disciplinares. O que se conclui é algo tão corriqueiro quanto dramaticamente verdadeiro: a formação profissional de professores para os anos iniciais requer, imediatamente, reformulação dos currículos, em que se assegure aos futuros professores o domínio dos conhecimentos que irão ensinar às crianças, articulados com metodologias de ensino adequadas. Vive-se no Brasil, no âmbito da formação de docentes, um 
estranho paradoxo: professores dos anos iniciais do ensino fundamental, que precisam dominar conhecimentos e metodologias de conteúdos muito diferentes, como Português, Matemática, História, Geografia, Ciências e, às vezes, Artes e Educação Física, não recebem esses conteúdos específicos em sua formação, enquanto que os professores dos anos finais, preparados em licenciaturas específicas, passam quatro anos estudando uma só disciplina, aquela em que serão titulados.

Uma hipótese que pode parecer a alguns pesquisadores algo temerário, se não catastrófico, é que as deficiências na formação de professores dos anos iniciais do ensino fundamental, mormente no domínio dos conteúdos e metodologias das disciplinas a serem ensinados nessas séries, estariam sendo um dos fatores determinantes do baixo desempenho do sistema de ensino brasileiro, tal como tem sido evidenciado nas avaliações em escala. Há fortes indícios de que o despreparo de professores produz nas crianças das séries iniciais acentuados desajustes em seu preparo cognitivo para a continuidade do seu processo de aprendizagem. A inexistência de pré-requisitos cognitivos essenciais, se forem aceitáveis os argumentos da psicologia do desenvolvimento e da aprendizagem, poderá inviabilizar novas aprendizagens ou reafirmar aprendizagens mal consolidadas, comprometendo irremediavelmente o papel da escola em formar cidadãos aptos a enfrentar as tarefas postas pela vida social. A ampliação das séries iniciais para cinco anos somente fará aumentar o descalabro atualmente existente, especialmente em relação aos fatores intraescolares ligados a deficiências pedagógico-didáticas.

\section{Referências bibliográficas}

BRASIL. Conselho Nacional de Educação (CNE). Parecer CNE/CP n. 28, de 2 de outubro de 2001. Dá nova redação ao Parecer CNE/CP 21/2001, que estabelece a duração e a carga horária dos cursos de Formação de Professores da Educação Básica em nível superior, curso de licenciatura de graduação plena. Disponível em: < http://portal.mec.gov.br/cne/ arquivos/pdf/028.pdf>.

BRASIL. Conselho Nacional de Educação (CNE). Resolução CNE/CP $n$. 1/2006, de 15 de maio de 2006. Diretrizes Curriculares Nacionais para o Curso de Pedagogia - Licenciatura. Disponível em: < portal.mec.gov. br/cne/arquivos/pdf/rcp01_06.pdf>.

CHAGAS, Valnir. Formação do magistério: novo sistema. São Paulo: Atlas, 1976.

DAVYDOV, Vasili V. Problems of developmental teaching - the experience of theoretical and experimental psychological research. Soviet Education, New York, Sep. 1998. 
GATTI, Bernadete A.; NUNES, Marina M. R. (Orgs.). Formação de professores para o ensino fundamental: estudo de currículos das licenciaturas em Pedagogia, Língua Portuguesa, Matemática e Ciências Biológicas. São Paulo: Fundação Carlos Chagas, DPE, 2009.

GAUTHIER, Clermont et al. Por uma teoria da Pedagogia: pesquisas contemporâneas sobre o saber docente. Ijuí-RS: Unijuí, 1998.

GIMENO SACRISTÁN, José. La educación obligatoria: su sentido educativo y social. Madrid: Morata, 2000.

LIBÂNEO, José C. A Didática e a aprendizagem do pensar e do aprender: a teoria histórico-cultural da atividade e a contribuição de Vasily Davídov. Revista Brasileira de Educação, Rio de Janeiro, n. 27, p.5-24, 2004.

Diretrizes curriculares da Pedagogia: imprecisões teóricas e concepção estreita da formação profissional de educadores. Educação \& Sociedade, Campinas, n. 96, p. 843-876, out. 2006.

. Didática e epistemologia: para além do embate entre a Didática e as didáticas específicas. In: VEIGA, Ilma Passos A.; D’ÁVILA, Cristina (Orgs.). Profissão docente: novos sentidos, novas perspectivas. Campinas: Papirus, 2008. p. 59-88.

. Docência universitária: formação do pensamento teóricocientífico e a atuação nos motivos dos alunos. In: D'ÁVILA, Cristina (Org.). Ser professor na contemporaneidade: desafios, ludicidade e protagonismos. Curitiba: CRV, 2009a. p. 69-83.

Panorama do ensino da Didática, das metodologias específicas e disciplinas conexas, nos cursos de Pedagogia do Estado de Goiás: repercussões na qualidade da formação profissional. In: SEMINÁRIO "O UNO E O DIVERSO NA EDUCAÇÃO", 10., 2009, Uberlândia. In: Anais do X [...] e IV Seminário de Didática. Uberlândia: UFU/Faced, 2009b.

. Integração entre Didática e epistemologia das disciplinas: uma via para a renovação dos conteúdos da Didática. In: DALBEN, Ângela et al. (Orgs.). Convergências e tensões no campo da formação e do trabalho docente: Didática, formação de professores, trabalho docente. Belo Horizonte: Autêntica, 2010a. p. 81-104.

A escola brasileira em face de um dualismo perverso:

escola do conhecimento para os ricos, escola do acolhimento social para os pobres. Palestra apresentada no X Encontro de Pesquisa em Educação da Anped-Centro Oeste, realizado na Universidade Federal de Uberlândia, 2010b. 
NÓVOA, Antonio. Professores: imagens do futuro presente. Lisboa: Educa, 2009.

PIMENTA, Selma G. A Didática como mediação na construção da identidade do professor: uma experiência de ensino e pesquisa na licenciatura. In: ANDRÉ, Marli E. D.; OLIVEIRA, Maria R. (Orgs.). Alternativas no ensino de Didática. Campinas: Papirus, 1997. p. 37-69.

SHULMAN, Lee S. Conocimiento y enseñanza: fundamentos de la nueva reforma. Professorado: revista de Currículo y Formación, v. 9, n. 2, 2005. Disponible en URL: < http://www.ugr.es/ recfpro/ rev92ART1.pdf $>$.

TARDIF, Maurice. Saberes docentes e formação profissional. Petrópolis: Vozes, 2002.

TORRES, Rosa Maria. Educação para Todos: a tarefa por fazer. Porto Alegre: Artmed, 2001.

WORLD CONFERENCE ON EDUCATION FOR ALL (WCEFA Conferência Mundial de Educação para Todos). Declaração mundial sobre educação para todos e Plano de ação para satisfazer as necessidades básicas de aprendizagem. Jomtien, Tailândia, 1990. Disponível em: <http://www.acaoeducativa.org.br/downloads/ Declaracao_Jomtien.pdf $>$.

José Carlos Libâneo, doutor em Educação pela Pontifícia Universidade Católica de São Paulo (PUC-SP), é professor do Programa de Pós-Graduação em Educação da Pontifícia Universidade Católica de Goiás (PUC-GO).

libaneojc@uol.com.br

Recebido em 14 de junho de 2010.

Aprovado em 16 de setembro de 2010. 